\title{
CS-US interval and conditioned fear facilitation of shuttlebox avoidance learning in the goldfish'
}

\begin{abstract}
KENNETH H. BROOKSHIRE and KENNETH FRUMKIN, Franklin and Marshall College, Lancaster, Pa. 17604
\end{abstract}

Goldfish were given 40 Pavlovian fear conditioning trials and then were trained on a shuttlebox avoidance task under either a 10-sec or a 30-sec CS-US interval. When compared with unstimulated control Ss, fear-conditioned fish showed facilitation of avoidance responding for the $30-\mathrm{sec}$, but no for the 10-sec, interstimulus interval.

In its simplest form, two factor learning theory (Rescorla \& Solomon, 1967) predicts that Pavlovian fear conditioning should improve later avoidance responding to the same CS. Evidence exists, however, which indicates that conditioned fear training may have both interfering and facilitating effects on subsequent avoidance learning in rats (cf. de Toledo \& Black, 1967; Weiss, Krieckhaus, \& Conte, 1968) and in fish (Frumkin \& Brookshire, 1969; Pinckney, 1967).

It has been suggested (Dinsmoor \& Campbell, 1956; Weiss et al, 1968) that interference with avoidance responding by prior fear conditioning may depend upon the extent to which competing responses (such as freezing in the rat) tend to interfere with the required avoidance response. Weiss et al (1968) found that fear conditioning did produce extensive freezing in rats, and that this behavior interfered with subsequent shuttlebox avoidance conditioning. When Ss were pretrained on the shuttle avoidance task, however, Pavlovian fear conditioning improved later avoidance responding (Rescorla, 1967; Weiss et al, 1968). It may be argued that pretraining served to make the conditioned avoidance response (CAR) more readily available during later training and thus decreased the likelihood of interference by competing responses.

While classical fear conditioning is sufficient to motivate fish to learn an instrumental response to escape a previously neutral CS (Brookshire \& Hognander, 1968), such training has been shown to produce interference with subsequent shuttlebox avoidance learning, at least with fish who are "poor performers" (Pinckney, 1967). Even if competing responses acquired during fear conditioning do interfere with later avoidance learning to the same $\mathrm{CS}$, it is possible to assume that the came on, followed 10 or $30 \mathrm{sec}$ later by the onset of the US.

Interrupting the photocell beams between the two compartments terminated the CS (avoidance) or CS and US (escape). If no escape occurred after $2 \mathrm{~min}$, the trial was terminated by $\mathrm{E}$.

\section{RESULTS}

The mean number of trials to criterion for each group is presented in Table 1. Analysis of variance indicated that, overall, Ss tested on the $10-\mathrm{sec}$ avoidance task required significantly more trials to meet the learning criterion than did those tested on the $30-\mathrm{sec}$ avoidance task $(\mathrm{F}=4.01$, df $=1, \mathrm{p}<.05)$. The interaction also was significant $(\mathrm{F}=2.95, \mathrm{df}=3, \mathrm{p}<.05)$. Scheffé post hoc comparisons demonstrated that among the groups tested with a 10-sec CS-US interval, control and experimental Ss did not differ significantly in terms of trials to criterion. For the 30-sec test interval, however, control $\mathrm{Ss}$ required a significantly greater number of trials to reach criterion than did fear conditioned Ss. For each row, no reliable differences appeared between any of the experimental groups. Moreover, the two control groups did not differ significantly from each other. A median split for each experimental group was used to define "good performers" and "poor performers" (after Pinckney, 1967). Separate analyses of variance on these two sets of data yielded results identical with those of the overall analysis.

Table 2 contains the mean number of trials required to make the first avoidance response for each of the eight groups. Analysis of variance showed that groups receiving a 30 -sec CS-US interval during avoidance conditioning made their first CAR significantly earlier in training than did Ss tested with a 10-sec CS-US interval $(\mathrm{F}=12.06, \mathrm{df}=1, \mathrm{p}<.01)$. However, the difference between the two control groups did not approach statistical significant $(\mathrm{t}=0.09, \mathrm{df}=14, \mathrm{p}>.45) ;$ fear conditioning interval $(F=.79, \mathrm{df}=3)$ and the interaction $(F=1.48, \mathrm{df}=3)$ also were not significant.

Table 3 shows the mean latency of the first avoidance response for experimental groups. By analysis of variance both primary sources were statistically significant (fear conditioning interval: $F=5.49, \mathrm{df}=3,56$, $\mathrm{p}<.01$; avoidance interval: $\mathrm{F}=69.86$, $\mathrm{df}=1,56, \mathrm{p}<.01)$, as well as the interaction term $(F=4.05, d f=3,56, p<.025)$. Scheffe tests showed that experimental $\mathrm{Ss}$ differed from the control group under the 30 -sec CS-US avoidance test interval, but not under the 10-sec avoidance interval.

\section{DISCUSSION}

In this study Pavlovian fear conditioning (regardless of the CS-US interval employed) was shown to facilitate subsequent CAR 
Table 1

Mean Number of Trials to Criterion

\begin{tabular}{lcccccc}
\hline & \multicolumn{5}{c}{ Fear Conditioning CS-US Interval (sec) } \\
& & \multicolumn{1}{c}{ Control } & 5 & 10 & 30 \\
\cline { 2 - 6 } $\begin{array}{l}\text { CS-US Interval During } \\
\text { Avoidance Training (sec) }\end{array}$ & 10 & 27.9 & 35.5 & 31.4 & 27.6 \\
\cline { 2 - 6 } & 30 & 35.8 & 20.2 & 16.0 & 17.5 \\
\hline
\end{tabular}

Table 2

Mean Number of Trials until the First Avoidance Response

\begin{tabular}{llllll}
\hline & \multicolumn{5}{c}{ Fear Conditioning CS-US Interval (sec) } \\
& & Control & 5 & 10 & 30 \\
\cline { 3 - 6 } & 10 & 3.75 & 7.25 & 8.25 & 6.00 \\
CS-US Interval During & 10 & 3.88 & 2.25 & 3.25 & 2.00 \\
\hline
\end{tabular}

Table 3

Mean Latency of the First Avoidance Response

\begin{tabular}{lccccc}
\hline & \multicolumn{5}{c}{ Fear Conditioning CS-US Interval (sec) } \\
& & Control & 5 & 10 & 30 \\
\cline { 2 - 6 } & 10 & 5.28 & 6.81 & 4.45 & 6.63 \\
CS-US Interval During & 30 & 10.94 & 14.29 & 16.34 & 23.64 \\
\hline
\end{tabular}

acquisition in fish when the CS-US interval during avoidance training was $30 \mathrm{sec}$. No effect of fear conditioning appeared with a 10-sec CS-US test interval. For fish which had received prior fear conditioning, the 30 -sec avoidance task produced more efficient learning than the 10 -sec task (measured in terms of trials to criterion and emergence of the first CAR). However, control groups (which had received no fear conditioning) tested at either 10 or $30 \mathrm{sec}$ did not differ from each other on either of these two measures.

Previously, CAR facilitation by conditioned fear had been observed in the rat either when pretraining had made the required avoidance response readily available to the S (Rescorla, 1967; Weiss et al, 1968 ) or when the avoidance task was a relatively easy one, such as ledge-jumping (Baum, 1969) or one-way avoidance (de Toledo \& Black, 1967), as compared with the more difficult (Theios \& Dunaway, 1964) shuttlebox avoidance problem. It appears that neither of these conditions (earlier availability of the CAR, more easily learned task) was present to account for the shuttlebox avoidance facilitation observed at a CS-US interval of $30 \mathrm{sec}$ in the present study: the control group data showed that the first avoidance response did not occur any earlier in training for the 30-sec group (Table 2), nor was the 30-sec avoidance task learned more quickly (Table 1).
One possible explanation for the disjunctive effects with different CS-US avoidance intervals observed in this study is that competing responses acquired during fear conditioning (which are assumed to interfere with later shuttlebox avoidance learning; Pinckney, 1967) are relatively short-lived and are not maintained over the 30-sec interval employed in the present study. Therefore, competing responses may manifest themselves early in the CS-US interval and still allow time for conditioned fear to precipitate an avoidance response. This interpretation is supported in the present study by the observation that the latency of the first CAR by fear-conditioned fish was longer than for control Ss(Table 3) even though the fear-conditioned animals were, overall, better learners.

The data for the 10-sec test condition, which showed no group differences in CAR performance, failed to support the results reported by Pinckney (1967), in which he found interference with avoidance respond. ing by conditioned fear in "poor performers." It should be noted, however, that Ss in the present study were tested $24 \mathrm{~h}$ after fear conditioning, 10 trials per day, to a criterion, whereas Pinckney's test consisted of 40 trials of avoidance training commencing $3 \mathrm{~min}$ after fear conditioning.

The fact that CAR acquisition did not vary as a function of the CS-US interval during fear conditioning supports the findings of Behrend \& Bitterman (1962), also from goldfish, which suggest that a wide range of CS-US intervals are equally efficient for Pavlovian fear conditioning. However, there appears to be a direct relationship between latency of the first avoidance response and fear conditioning CS-US interval when CAR facilitation is observed. Therefore, in the present study, conditioned fear and its effects may be thought of as independent of the CS.US interval during fear conditioning, while competing responses or their latency may be a function of this variable. This might be taken to mean that the two hypothesized effects of fear conditioning (the development of fear and the development of competing responses) are sensitive to different experimental variables.

\section{REFERENCES}

BAUM, M. Dissociation of respondent and operant processes in avoidance learning. Journal of Comparative \& Physiological Psychology, 1969, 67, 83-88.

BEHREND, E. R., \& BITTERMAN, M. E. Avoidance-conditioning in the goldfish: Exploratory studies of the CS-US interval. American Journal of Psychology, 1962, 75, 18-34.

BROOKSHIRE, K. H., \& HOGNANDER, O. C. Conditioned fear in the fish. Psychological Reports, 1968, 22, 75-81.

de TOLEDO, L., \& BLACK, A. H. Effects of preshock on subsequent avoidance conditioning. Journal of Comparative \& Physiological Psychology, 1967, 63, 493-499.

DINSMOOR, J. A., \& CAMPBELL, S. L. Escape-from-shock training following exposure to inescapable shock. Psychological Reports, $1956,2,43-49$.

FRUMKIN, K., \& BROOKSHIRE, K. H. Conditioned fear training and later avoidance learning in the goldfish. Psychonomic Science, $1969,3,159-160$.

PINCKNEY, G. A. Avoidance learning in fish as a function of prior fear conditioning. Psychological Reports, 1967, 20, $71-74$.

RESCORLA, R. A. Inhibition of delay and Pavlovian fear conditioning. Journal of Comparative \& Physiological Psychology, 1967, 64, 114-120.

RESCORLA, R. A., \& SOLOMON, R. L. Two-process learning theory: Relationships between Pavlovian conditioning and instrumental learning. Psychological Review, 1967, 74, 151-182.

THEIOS, J., \& DUNAWAY, J. E. One-way versus shuttle avoidance conditioning. Psychonomic Science, 1964, 1, 251-252.

WEISS, J. M., KRIECKHAUS, E. E., \& CONTE, R. Effects of fear conditioning on subsequent avoidance behavior and movement. Journal of Comparative \& Physiological Psychology, 1968, 65, 413-421.

\section{NOTE}

1. This research was supported by Research Grant MH-05874 from the National Institute of Mental Health, USPHS. 